\title{
UNA PRESÓ A MIDA. LES ESTANCES DE FERRAN \\ D'ARAGÓ DURANT EL SEU CAPTIVERI AL CASTELL DE XÀTIVA ${ }^{1}$
}

\author{
Aaron Jara Calabuig \\ Universitat Politècnica de València \\ Vicente Gabriel Pascual Montell \\ (Universitat de València)
}

\begin{abstract}
Resum: El present article es deté en l'estudi dels espais ocupats per Ferran d'Aragó, duc de Calàbria, durant el seu captiveri a Xàtiva, partint de les escasses restes materials existents i especialment a través de la documentació generada per les obres d'espais com la Sala Nova, que han estat analitzades amb major atenció. Es para esment, d'igual forma, a factors com la permanència de la memòria d'aquest captiveri en els segles posteriors, tractant d'apuntar el paper assumit pels elements arquitectònics en aquest sentit.
\end{abstract}

Paraules clau: Arquitectura civil, artífexs, castell de Xàtiva, Ferran d'Aragó, duc de Calàbria.

A custom-made prison. The rooms of Ferdinand, Duke of Calabria, during his captivity at Xativa Castle

Abstract: This research paper analyzes the spaces occupied by Ferdinand, Duke of Calabria, during his captivity in Xativa. The study is based on the few existing ruins and especially on some technical documentation of facilities such as the "Sala Nova", which have been analyzed with greater attention. Furthermore, the image of this construction in the collective memory during the last centuries becomes essential in order to recognize the importance of the architectural composition in the historical monument.

Key words: Civil architecture, architects, Xativa Castle, Ferdinand, Duke of Calabria.

La vida de Ferran d'Aragó, duc de Calàbria i virrei de València, ha estat sobradament tractada des de distints punts de vista: són abundants els acostaments a la seua biografia (Castañeda Alcover, 1911, pp. 268-286; Sarthou Carreres, 1922, pp. 30-31; Ventura Conejero, 1998, pp. 189-209) i implicació social (Martí Ferrando, 1993), al seu paper en l'aparició del Renaixement al país (Falomir Faus, 1994); des de la seua actuació durant les Germanies (García Carcel, 1981,

Data de recepció: 15 d'abril de 2020 / Data d'acceptació: 21 de juliol de 2020.

1 Aquest text és la versió ampliada de la comunicació presentada al III Congrès Xàtiva: Història, Cultura i Identitat, celebrat a Xàtiva entre els dies 16 i 19 d'octubre del 2018. 
pp. 131-132; per al cas de Xàtiva (Pons Alós, Cruselles, 2006, 280-289, esp. 285287) a la cabdal importància de la seua biblioteca (Ferrer del Rio, 2016. pp. 65119). Inclús el seu captiveri xativí ha estat bastant treballat per la bibliografia clàssica (Boix Ricarte, 1857, pp. 109-111; Ballester Julbe, 1909) i moderna (Ferrer del Rio, 2016, pp. 65-119; Ventura Conejero, 1998).

Molt més minses han estat les referències a les construccions que habità durant el seu empresonament a Xàtiva: resulten fonamentals, per al seu coneixement, els extractes documentals publicats per Ventura Conejero al seu llibre El castell de Xàtiva (Ventura Conejero, 1998). Tot i aquesta desatenció, es tracta d'estructures que resulten de gran importància per al coneixement de l'arquitectura civil contemporània a la ciutat, tant pel que fa a la precisió i riquesa amb que es registra documentalment el seu desenvolupament (recordem que les fonts escrites conservades que es refereixen a l'activitat arquitectònica a la Xàtiva d'inicis del cinc-cents són ben minses) com per seguir-se models a nivell constructiu, tipològic i tècnic idèntics als que poden identificar-se a edificacions com, per exemple, les cases senyorívoles coetànies: es perfilen, així, doblement destacables per al coneixement de la construcció urbana de l'època.

En aquestes pàgines tractarem de resoldre la referida mancança a partir de la reconstrucció literària de les estances, construïdes i adaptades ex professo per a l'hostatge del duc amb cert nivell de sumptuositat i confort. Intentarem acostar-nos a l'estudi d'aquestes estructures partint de l'anàlisi dels documents que reflecteixen el progrés de les obres amb bastant profusió de detalls: les principals fonts, en aquests sentit, són els llibres del Mestre Racional (9189, 9190, 9192 i 9193, bàsicament: la sèrie documental serà citada, d'ara endavant, com $M R$ ), conservats a l'Arxiu del Regne de València (citat d'ara endavant com ARV), la informació dels quals fou parcialment publicada per Ventura Conejero. Reflecteixen l'avanç de les obres amb bastant precisió i profusió de detalls, a més d'assenyalar reparacions o reformes posteriors. Tractarem de completar les informacions que ens proporcionen amb les escasses referències gràfiques i literàries que podem aportar, que ajuden a completar la imatge d'aquestes règies estances.

\section{UNES BREUS NOTES BIOGRÀFIQUES: EL DUC A XÀTIVA}

La trajectòria vital de Ferran d'Aragó (1488-1550) fou dilatada i intensa: es desenvolupa abans i després de la reclusió a Xàtiva, presentant-se aquest episodi com un parèntesi, un esdeveniment més, si bé prolongat i sense dubte poblat de molèsties, de la seua existència. Ens limitarem, per tant, a esbossar unes breus pinzellades entorn la reclusió del duc al castell. El 4 de novembre de 1512 
arribava presoner a Xàtiva el duc de Calàbria, hereu del regne de Nàpols: mort son pare, el rei Frederic I, i conquerit el regne sud-itàlic per Ferran II d'Aragó, el jove duc quedava desposseït dels seus drets successoris, si bé gaudia de certa posició integrat a la cort d'aquest des dels catorze anys. Reclòs al castell d'Atienza, en Guadalajara, després d'un conat de fugida a França s'especulen motius diversos per al trasllat a la fortalesa xativina: distints estudis han apuntat, de forma més bé romàntica, un episodi de gelosia, nascuda en el Rei Catòlic per l'estreta relació epistolar entaulada entre el duc i la seua segona esposa, na Germana de Foix (que, de fet, acabarà casant amb Ferran), però més segurament caldria assenyalar la fundada possibilitat d'una evasió (Ferrer del Rio, 2016, p. 87).

El Catòlic remeté el presoner a l'alcaid Mercader, del castell de Xàtiva, amb un lacònic "Alojarás a don Fernando de Aragón, duque de Calabria. Pon a buen recaudo los presos de ese castillo" (Sartou Carreres, 1979, p. 452): es destina per al seu hostatge una part del castell major, ço és, un dels recintes, el situat a l'est, que composen la fortalesa. En tot cas, Ferran II seguia una tradició secular entre la monarquia aragonesa: emprar el castell de Xàtiva com a presó reial, car com explicava Viciana "Es este castillo [...] los reyes han tenido la carcel de mas reputacion y auctoridad [...] Y assi los reyes siempre en el han encastillado los presos mas calificados de todos sus reynos" (Viciana, 1564, p. 367), despuntant entre ells, per la seua celebritat i circumstàncies, el duc d'Urgell Jaume d'Aragó, amb "los Infantes Cerdas, nietos del Rey Alfonso el Sabio, y el Duque de Calabria", segons rememorava Espinalt (Espinalt García, 1786). Des d'aquest espai de reclusió, Ferran d'Aragó alternà llargs períodes d'absoluta tranquil-litat amb moments d'intensa acció, a finals del seu turbulent captiveri: des de les altures del castell va viure com a protagonista els esdeveniments de la revolta de les Germanies a Xàtiva (Sarthou Carreres, 1933-1935, pp. 314-315; Sarthou Carreres, 1979, pp. 450-451): són moment de gran tensió, car des del poder reial es valorava la plausible possibilitat que el duc aprofités l'ocasió per reclamar els seus drets sobre la corona valenciana. Veient-se, a més, acompanyat de personatges fidels al poder virregnal, Ferran d'Aragó degué intervenir personalment per assegurar la integritat del seu custodi, Gil d'Ateca, i de l'alcaid Mercader, finalment empresonats (Pons Alós, V.; Cruselles, J. M., 2006, pp. 285-286). Als edificis que habitava el duc fou conduït Rodrigo Hurtado de Mendoza, el marquès del Zenete, després de les seues discutibles negociacions amb els agermanats de la ciutat: durant un breu lapsus de temps varen compartir hostatge, però tant prompte com Zenete fou atès de les nafres que presentava se'l feu davallar a les obscures cel-les que habità Jaume d'Urgell. Per mediació de Ferran es va negociar la seua alliberació: d'ençà el de Zenete va demostrar gran estima pel duc (Vallés Borràs, 2007, p. 20), qui acabaria sent, pòstumament, el seu gendre. 
Encara va transcórrer un temps fins que Ferran d'Aragó retornà a la llibertat: el 5 de desembre de 1522 Carles I, rei de les Espanyes i emperador d'Alemanya, excarcera el presoner, demorant les disposicions fixades al testament de son avi (1516), en què recomanava el seu alliberament (Ventura Conejero, 1998, p. 191), però reconeixent la fidelitat del duc al bàndol reial durant les Germanies. Havien passat deu anys des de la seua arribada a Xàtiva. El transcórrer de la seua vida amb posterioritat a aquest obscur període és sobradament coneguda: en 1526 casava, a Sevilla, amb la vídua na Germana de Foix, i retornava per instal-lar-se a València, ostentant virregnat fins la seua mort (15361550): de camí cap a la capital del regne feren parada en Xàtiva, hostejant-se una setmana en el castell. Qui sap si, com pensa Ventura, en aquesta ocasió "el duc recordaria la seua presó i li ensenyaria a Na Germana el lloc i les sales on havia passat deu anys" (Ventura Conejero, 1998, p. 192).

\section{LES RUTINES DEL PRESONER. MENS SANA IN CORPORE SANO}

Coneguem algunes dades ben interessants sobre l'estança del duc al castell que il-lustren el ritme de la seua rutina diària. Abans de res, cal assenyalar que, per al seu sosteniment personal, Ferran d'Aragó comptava amb una sèrie de servents. Cal citar, en primer lloc, a mossèn García Gil de Ateca, cavaller aragonès que actuava com a custodi del duc (Ventura Conejero, 1998, p. 76) des d'almenys 1515 , que mantenia el contacte directe amb el monarca, podent demanar augments en l'aprovisionament i en els fons per a les reparacions a efectuar en el castell, i amb capacitat per augmentar el nombre de guardes (Ballester Julbe, 1909, p. 55). Sabem que ostentava el títol de majordom del duc (Ventura Conejero, 1998, p. 80), i que amb ell arribà la seua filla: es consigna la seua residència en les mateixes sales que el duc, obrant-se una habitació específica per alcova sobre la Sala Nova. És de suposar que es tractaria d'una persona de certa instrucció, amb un cert nivell cultural com per permetre's mantenir una conversació amena i variada amb el duc, persona de vasta formació. Amb els anys, i almenys des de 1520 , es documenta un tal mossèn Òdena, cavaller, també amb les funcions de majordom.

Sembla que el duc va mantenir una escarida però selecta "cort", que integraria alguns dels principals prohoms xativins del seu temps: Ventura conjectura una relació entre el duc i el batlle reial, Francesc de Fenollet (Ventura Conejero, 1998, pp. 198, 200-204 i 210), integrant d'una de les principals nissagues de la ciutat, que en successives generacions assolirien el senyoriu d'importants territoris a la contrada de Xàtiva. De fet, dit historiador planteja la hipòtesi que la filla natural del duc, Jerònima d'Aragó -que professà en les do- 
miniques de Xàtiva, atraient a son pare com a comitent artístic cap a dit convent- fos engendrada amb la filla del batlle, Beatriu (Ventura Conejero, 1998, pp. 198-199). Fenollet fou un actiu participant en els cercles literaris del seu temps (Perea Rodrígez, 2006, pp. 273-281): son pare fou ja un home versat en lletres. Amb la seua cultura i interessos podria correspondre's al duc, bolcat en la lectura i la recerca de coneixement.

Que el futur virrei va aprofitar la seua llarga estança al castell per cultivar el seu coneixement científic, de la filosofia i la teologia, sembla que fou quelcom conegut ja al cinc-cent: "el duque tuvo en su puericia un secretario y maestro docto llamado micer Crysostomo y este le enseño la lengua latina y después estudio mucho en el tiempo que estuvo en Xativa preso", segons les Batallas y Quinquágenas de Fernández d'Oviedo (Falomir Faus, 1994, p. 122). $\mathrm{S}$ 'ha especulat entorn la presència d'almenys part de la seua rica biblioteca al castell (Sarthou Carreres, 1914, p. 26; Ferrer del Rio, 2016, p. 90), però no existeix, sembla, cap mena de confirmació: consta, en canvi, la remissió de contingents de llibres en 1527 i 1535 (Cabeza Sánchez-Albornoz; Toscano, 1999, pp. 27, 28-29). Recordem que el duc fou un dels bibliòfils més destacats del seu temps, i que abans de la seua eixida d'Itàlia comptava amb una biblioteca de primer ordre, composada d'un gran nombre de volums (impresos i manuscrits) de temàtica variada i altíssima qualitat material, quantitat progressivament ampliada a partir de deixes i donacions familiars.

Fóra com fóra, no solament es dedicava el duc al cultiu de la paraula i l'intel-lecte: coneixent la importància de l'esport per al manteniment de la salut física, al presoner se li permetia exercitar-se en l'hortet enjardinat que es mantenia als peus de la seua residència, baix la torre rodona i junt la porta de Santa Maria. Per a tal fi es varen emprendre obres d'importància, tals com la construcció d'un aljub amb el que regar l'hort ${ }^{2}$ i una llongeta o galeria porticada oberta al jardí. Igualment, es va emprendre la construcció de la Sala Nova com a trinquet per disposició real: amb carta del rei Ferran, donada en Segòvia a 15 de juliol de 1514, es manava aixecar el saló "per a poder jugar a pilota lo ilustre senyor Duc e per fer exercici per la sanitat de sa persona" (Ventura Conejero, 1998, p. 77). I és que, a banda de ser un joc popular, practicat habitualment en el carrer, la pilota va esdevindre entreteniment habitual entre la noblesa de l'època: Joan Lluís Vives se'n fa ressò en un imaginat diàleg entre uns suposats cavallers de les nis-

${ }^{2}$ Es tractava d'una obra d'importància, que ocupà, almenys, una desena d'homes (entre manobres i traginers) en certs moments, capitanejats per l'obrer de vil·la Miquel Fuster, entre el 10 de desembre de 1515 i el 25 de març del 1516 (ARV, MR, 9190, fol. 1r-20r). A més, a finals d'any es torna a treballar en aquesta estructura: en setembre del mateix any, per exemple, es procedeix a pavimentar-lo (ARV, MR, 9190, fol. 54r). 
sagues Centelles, Borja i Cavanilles (Iñúrria Montero, 2013, p. 46), i no de bades el trinquet de Cavallers es trobava en una de les zones de concentració de residències senyorials a la capital. És a dir, en les obres d'habilitació del castell, tant en aixecar aquesta estança com en la construcció de l'hortet, es contempla la necessitat d'exercici del presoner. Igualment, el duc podia passejar lliurement per tot el recinte fortificat, inclús practicar el tir amb arc vers la vall de Bixquert, caçant "als coloms e altres ocells que acostumen passar per allí", des d'una estança (citada com lloc de disposició), amb un ample finestral i ampit d'obra (ARV, MR 9192, fols. 37v-38v) obrada a tal efecte en 1520.

Tot tractant-se d'un presoner que oficialment habitava en el castell sota règim de custòdia, i valorant que es trobava en la plenitud de la seua joventut, no es restringeixen les activitats que es poden correspondre a la seua edat $\mathrm{i}$ condició noble. Les concessions resulten, en alguns cassos, sorprenents. Per exemple, el duc podia cavalcar en certes planúries habilitades de la fortalesa: en 1518 s'obrava una de les replaces del castell, anivellant-la amb tongades d'argamassa, per a tal fi. Aquests condicionaments de l'espai obeïen, igualment, a un projecte concret: aquell any el duc organitzà una festivitat en honor del nou monarca, Carles I, sense dubte per celebrar la seua arribada al regne per jurar corts, a inicis d'aquell any. Es preveia l'organització de jocs de canyes en la fortalesa, en els que sense dubte participarien els més nobles i destacats habitants de Xàtiva, els ciutadans més parells a la seua categoria: sembla que, efectivament, arribaren a realitzar-se, ja que es consigna l'obra de "huns cabirons pera posar hi huns draps [entenem per tals draps de ras, tapissos, que integrarien el mobiliari amb que el duc dotava de luxe les seues estances] vers ponent que no donas lo Sol en la cara del dn Illte $S^{r}$ Duch per al dit Joch de Canyes" i distintes partides per despeses annexes (ARV, MR, 9191, fol. 8v, $16 v)$. El joc de canyes, esport ennoblidor i violent, entreteniment d'arrel islàmica que connectava perfectament amb la sensibilitat cavalleresca romanent a l'època, gaudí de gran popularitat en la Península durant la baixa edat mitjana, estenent-se inclús al XVI: el seu auge fou molt notable en la cort castellana encara durant el cinc-cents, quan se'n organitzaren per celebrar festejos destacats (Silva Santa-Cruz, 2005, pp. 269-270). Resulta, sense dubte, interessant constatar el nivell de llibertat del que gaudia el duc, no solament pel que fa a les relacions socials, que inclús s'estenia a la potestat d'organitzar festejos: són episodis que ajuden a descongestionar la romàntica visió del lànguid i descoratjat presoner, presentada per certs historiadors.

També es contemplava la cura a la vessant espiritual durant el captiveri: el duc podia assistir a missa en la capella de Santa Maria, aixecada i dotada a mitjans del segle anterior per la regent Maria de Castella, pocs metres costera avall de les estances que ocupava. Però l'àmbit principal entorn el que es desenvolupà 
el captiveri, sense dubte, foren les estances que li foren assignades per a residència: durant els primers anys aquestes es limitaven a les dites Sales Velles o Morisques, un conjunt de construccions preexistents obrades cap a Bixquert a la part més alta del Castell Major, que ens resulten gairebé desconegudes. Per ampliar el recinte disponible, i pensant en crear un espai en què Ferran d'Aragó pogués seguir exercitant-se, es dóna provisió reial per construir la que passarà a ser coneguda com Sala Nova, planejada com a trinquet i que segueix la tipologia i trets característics de les sales principals dels casals ciutadans, segons es construïen en aquest moment. És aquesta una de les obres que documentem amb major precisió i detall, i en la que ens centrarem tot seguit.

\section{UN PALAU PER AL PRESONER}

A tenor de la degradació de les seues restes, hem d'acostar-nos a la fortalesa de Xàtiva, o al cas que ens ocupa, les sales del duc, a través de les referències escrites, dels documents de l'època: són especialment interessants els comptes del Mestre Racional ja esmentats, que ens permetran avançar la reconstrucció textual de l'espai. Podem tractar d'aproximar-nos a l'aspecte exterior i l'ordenació que presentaven a partir de l'anàlisi de diverses imatges en què identifiquem la representació més o menys diagramàtica de la façana nord del castell, i que ens serveix per resseguir l'evolució de la seua fisonomia al llarg dels segles. Molt properes en el temps a la construcció de l'estança del duc a la ciutat són les representacions del mestre de Borbotó (ca. 1520), al retaule dels Gojos de la Mare de Déu en l'església de Sant Pere de Xàtiva (Figura 1) 3 i la panoràmica de la ciutat dibuixada per Anton van der Wyngaerde (1563). En ambdues imatges trobem representada una construcció similar, coberta amb teulada a dos vessants i amb una sèrie de vans sota el ràfec: és la dita Sala Nova, aixecada durant 1516, que s'obria vers la ciutat. Es capta ací la seua façana amb gran detallisme: en el primer cas inclús es perceben dos finestres coronelles. La representació del castell al plànol de A. Montaigu (1721) de la Plaza y Castillo de San Phelipe és molt somera, però ens serveix per reafirmar-nos en les nostres hipòtesis: apareix una sala entre la terrassa de la que emergeix la torre del Malanyat i una sèrie d'estances més menudes al flanc sud, que ens reconeixem com la Sala Nova i les Sales Velles, respectivament (Figura 2). Deu anys des-

${ }^{3}$ El castell apareix al fons de la casa de l'esquerra del banc o predel·la, en què es representa a sant Antoni Abat. La semblança amb el castell de Xàtiva ja fou assenyalada per Sarthou Carreres, 1922, p. 30, nota 1, així com les dificultats existents per identificar allò representat amb la imatge que presentaria la fortalesa a inicis del XVI: tot i això pensem que la relació resulta bastant apurada. 


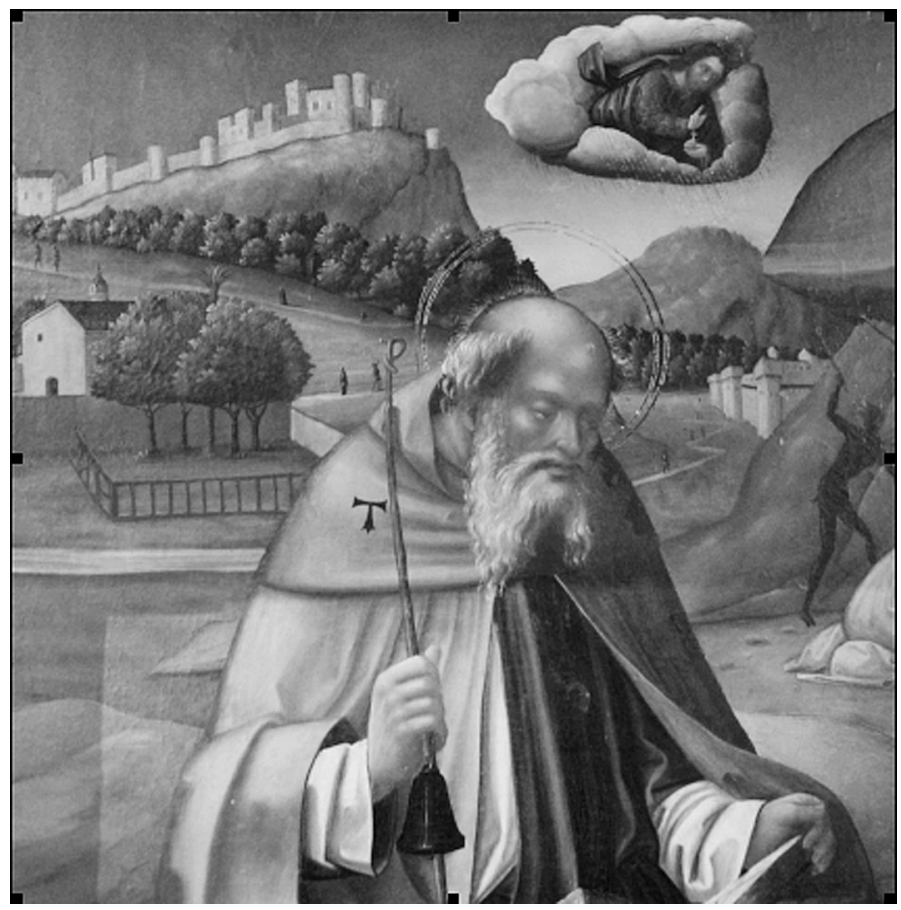

Figura 1. Retaule dels Gojos de la Mare de Déu. Detall. Mestre de Borbotó, ca. 1520 .

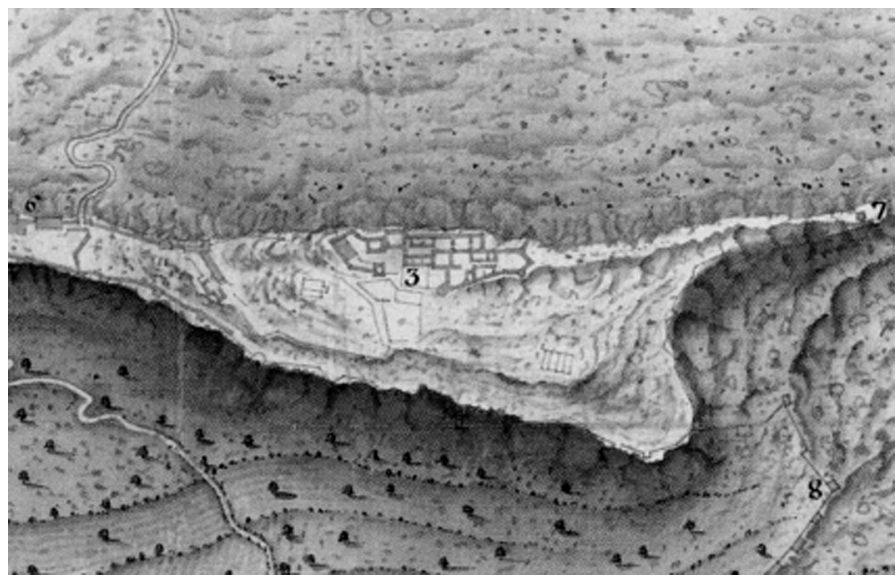

Figura 2. Plaza y Castillo de San Phelipe. Detall del castell major amb les estances del Duc de Calàbria. Antoine Montaigu, 1721.

Saitabi. Revista de la Facultat de Geografia i Història, 70 (2020), pp. 81-106

ISSN 0210-9980 DOI: 10.7203/saitabi.70.14229 @) (ब) 
prés, en 1731, Burguete gravà l'estampa que representa la Mare de Déu de la Seu ("Nuestra Señora de la Seo de San Phelipe, antes Xàtiva"), amb una detallada imatge de la Costa del Castell: a l'extrem dret es sobreïx una construcció (també sobre la cegada torre rodona) massissa, coronada de bandera onejant. Molt més diagramàtica és la representació de Palomino per il·lustrar l'Atlante Español d'Espinalt (1786).

L'aspecte que ens presenten aquestes imatges es correspon amb la informació que s'extrau de l'anàlisi documental i de l'estudi de les restes que es conserven actualment (Figura 3, Figura 4), i pot resumir-se en unes línies: s'observa un edifici cobert amb teulada a dos aigües, amb un pis inferior (on es trobarien els cellers, rebosts, habitacions de la guàrdia, cavallerisses, seguint la disposició habitual de les cases medievals, a més de la Presó Fosca), sota el pis noble, que alberga les estances del duc, amb la Sala Nova, la seua cuina i les dependències annexes, i coronant el conjunt una algorfa o andana, oberta cap a la ciutat amb una porxada, on es situaven algunes habitacions.

Abans que res cal recalcar que no existeixen gairebé restes d'aquestes construccions a resultes del cèlebre terratrèmol de Montesa (1748) i l'abandonament de les estructures del segle XVIII ençà: el desconeixement de les mateixes arribà a bastir hipòtesis errònies que inclús situaven alguna de les sales en l'espai del desllunat que les precedia vers el nord, com rebatrem. Per això, és necessari parar atenció prèviament al fet que les noves construccions resseguien un eix N-S, és a dir, configurant-se com una cruixia perpendicular a l'eix del conjunt fortificat (E-O). Existiria un pas, un vestíbul, baix la Sala Nova per permetre el trànsit cap al pati configurat amb aquesta cruixia afegida, ço és, el dit segon descobert de la salòquia o part més alta dels alcàssers islàmics.

Per l'escala que encara hui es conserva (Figura 5), i que es degué trobar oberta vers aquest segon pati de la salòquia, s'accedia al pis noble. Dóna accés a una plataforma elevada, construïda sobre la coneguda com Presó Fosca, l'ergàstul que varen ocupar distints presoners, entre ells el cèlebre comte d'Urgell. Analitzant el paviment observarem com l'actual planúria es trobava originalment coberta per porxades laterals: l'empedrat de còdols menuts, de riu (corresponent-se als desllunats), es combinen amb zones pavimentades de rajola disposada en aparell diatònic (els coberts). També resulta indicativa d'aquesta disposició la davallada traçada pel paviment cap a la boca de l'aljub obrat a l'extrem de la plataforma: baix la volta de l'escala encara s'observen les petjades de la canalització de desguassar -encadufades formades per parells de teulesque discorria cap a la cisterna. S'ha ubicat en aquesta plataforma, tradicionalment, la dita Sala Vella del duc (Ventura Conejero, 1998, p. 272), però, com ja avançàvem, pensem que aquestes estances degueren trobar-se al flanc sud del castell, obertes junt el mur de Bixquert, sobre el solar del que s'han consi- 


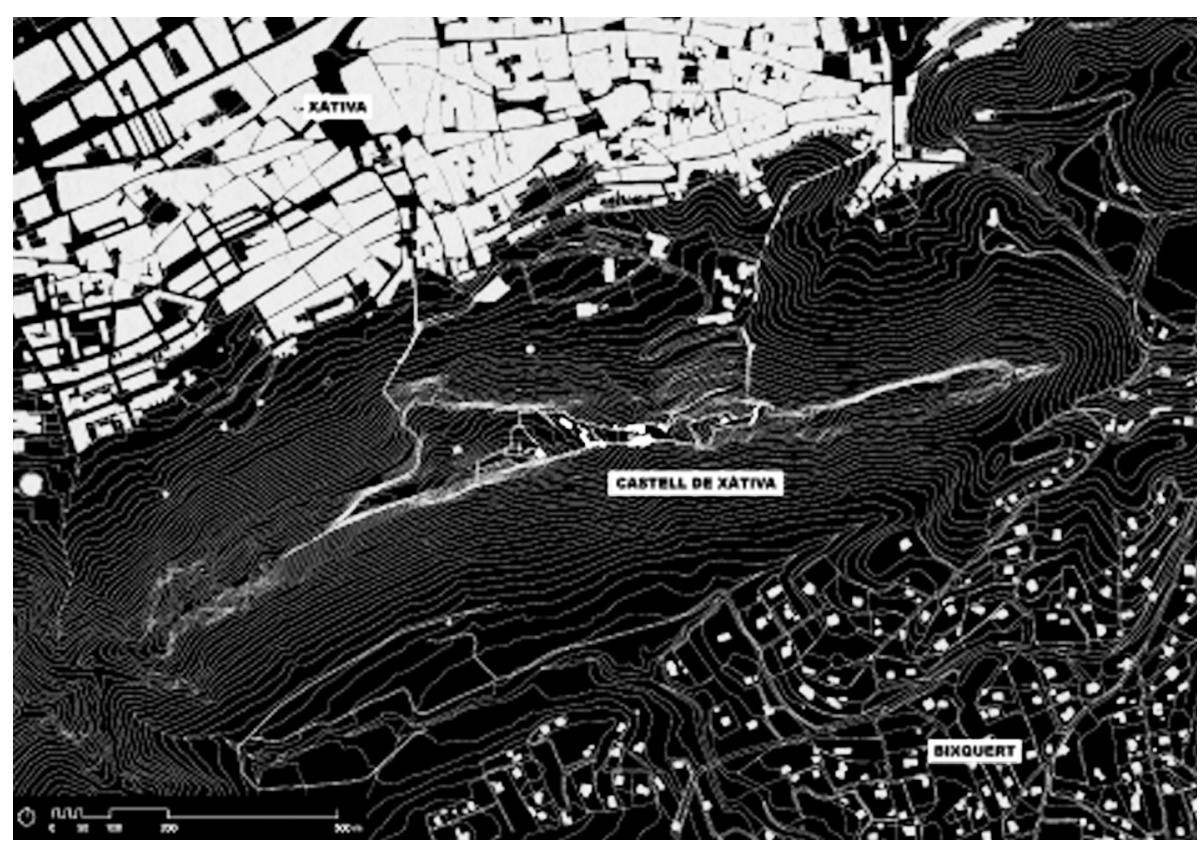

Figura 3. El Castell de Xàtiva i el seu entorn en l'actualitat. Aaron Jara, 2018.

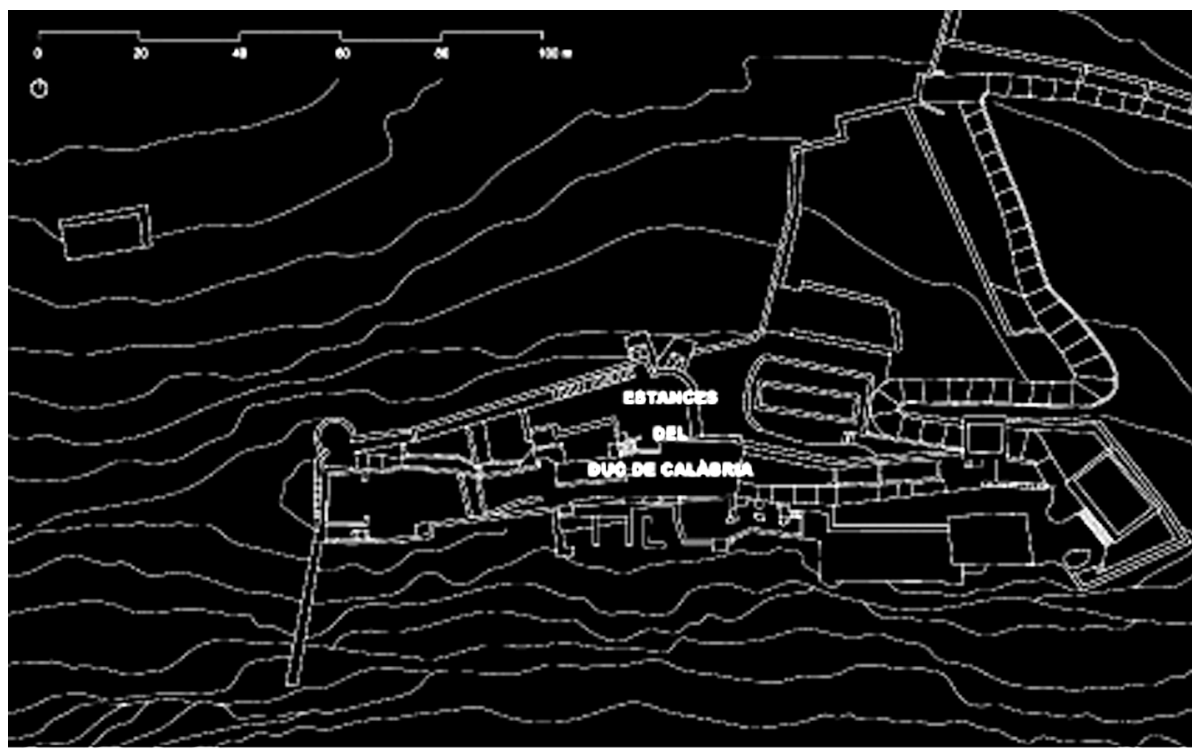

Figura 4. El castell Major i les estances del Duc de Calàbria. Aaron Jara, a partir dels plànols del castell, 2018.

Saitabi. Revista de la Facultat de Geografia i Història, 70 (2020), pp. 81-106 ISSN 0210-9980 DOI: 10.7203/saitabi.70.14229 (c) (1) () 


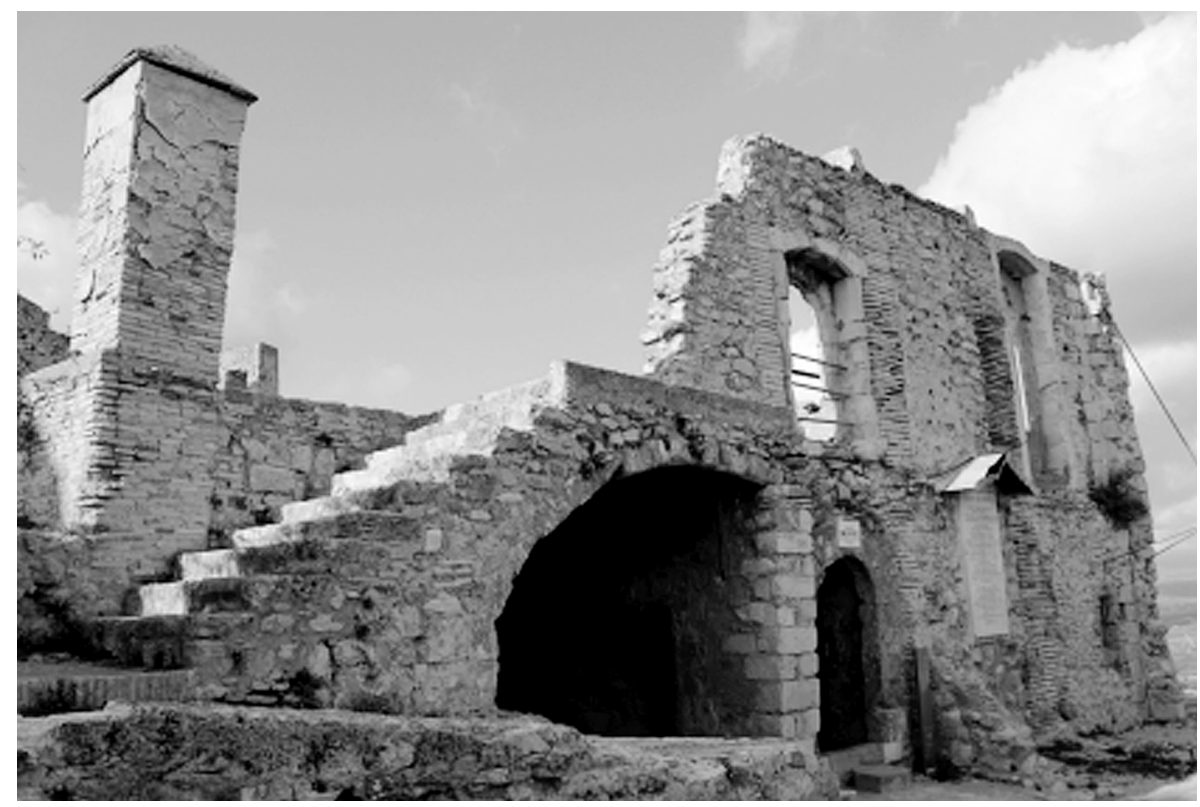

Figura 5. Escala de les estances. Aaron Jara, 2018.

derat estances dels alcaids, o junt aquestes: observe's igualment la configuració d'aquesta replaça com una terrassa, permetent vistes vers l'aljub i l'hortet del duc, als peus del penyot, i més amplament cap a la ciutat i la vall. Així, pensem que no es pot identificar amb les anteriorment dites Sales Velles, igualment disposades en paral·lel a l'eix del castell i obertes vers la valleta de Bixquert: aquestes eren estructures preexistents i segurament connectades a la torre dita de Sant Jordi, a la que també s'accedia des de les noves construccions, en concret des de la Sala Nova ${ }^{4}$. A aquest menut pati precedent a la Sala Nova es podria accedir tant des d'un hipotètic vestíbul cobert (disposat junt la muralla, connectant l'espai amb la torre de la campana: encara s'observen obrats al mur alguns dels permòdols sobre els que descansaven les jàsseres del seu cobert) com des del pati de la salòquia, a través de l'escala que encara es conserva.

${ }^{4}$ Pensem que no pot ser identificada amb les restes de la suposada torre romana-segons Ventura Conejero, 1998, p. 267- situada junt la capella de Santa Maria, per la llunyania que presenta a les sales del duc: recordem que la Sala Nova comptava amb una escala de caragol que permetia l'accès directe a aquesta torre (ARV, $M R, 9190$, fol. 64r). 
Explicades aquestes premisses necessàries per localitzar la construcció, passem a analitzar les obres per a construir el saló que es citarà com Sala Nova: s'inicien el 22 d'agost del 1513, segons alguns autors (Ventura Conejero, 1998, p. 76), si bé es desenvolupen, de forma gairebé completa, durant 1516, entre el 27 de març i el 22 d'octubre (darrer dia que consignem obres estrictament relacionades amb aquest espai) de dit any. Ens centrarem en l'estudi del llibre de comptes de 1516 (ARV, MR, 9190) per ocupar-se de l'obra de major envergadura d'entre les empreses per al duc durant els anys del seu captiveri, si bé citarem els restants quaderns de comptes, que també aporten informació valuosa. Cal valorar, d'altra banda, que no són les úniques empreses constructives destacables que es porten a terme en aquests anys: en 1519 es reparen o reconstrueixen amples sectors de mur en distints punts del castell, en unes obres que ocupen pràcticament la totalitat dels darrers mesos de l'any.

Als inicis de la relació les notes són més bé parques i no deixen entreveure amb seguretat l'avanç de l'obra: tractant-se dels primers moments de la mateixa, les feines principals devien ser les d'elevar murs. El 26 de maig, és a dir, dos mesos després d'iniciar-se la construcció, es ressenya com els obrers "feren faena en la cuyna q sta apres de la [sala] nova, feen una cuberta per a fer un caragol per pasar a la [...] sobre la [di]ta sala nova..." (ARV, MR, 9190, fol. $35 \mathrm{v}$ ). En els dies següents es segueix l'obra de l'escala de caragol i en la cuina de la sala (ARV, $M R$, dies 2 i 9 de juny, fols. 36r-36v i 37r, respectivament). Les obres devien trobar-se bastant avançades, donat que el mateix 26 de març s'inicia la realització dels filats per a les finestres: igualment, el 21 de juny es comença l'obra de la dita finestra major de la sala nova, és a dir, la gran coronella bífora oberta vers la ciutat. El 30 de juny els fusters comencen a realitzar les portes de la sala, mentre un manobre, Lluís Berenguer, comença a esmolar les rajoles per al paviment (ARV, $M R$, fols. 41v i 42v). Pavimentada l'estança des del 8 d'agost, i amb les obres d'instal-lació de les portelles de la finestra gran i de la teulada que li donava recer entre els dies 11 i 22 d'agost, la sala restava pràcticament habitable (ARV, $M R$, fols. 46v, $47 \mathrm{v}$ i 48v, respectivament). Les partides d'obres realitzades en la sala acaben en aquests moments: el dia 1 de setembre consta la darrera intervenció en aquest espai, amb la colllocació de les portes, que es realitzava a l'hora que les composicions a l'aljub (ARV, $M R$, fol. 50v). Sols al més següent, entre el 3 i 6 d'octubre, es consigna la col-locació d'un bastiment en la finestra major (ARV, $M R$, fol. 54r), quelcom que sembla una obra puntual.

És fàcil aproximar una descripció de la sala i la resta d'estances annexades gràcies a una visura (ARV, $M R, 9190$, fols. 63v-64r), de gran precisió i riquesa de detalls, que efectuà el notari Guillem Montfort per manament del batlle de la ciutat, el 23 de gener del 1517, finalitzada l'obra i per assegurar que l'enca- 
rregat de la seua construcció, el mestre Jerònim Monyos, havia acomplit les condicions capitulades. En les següents pàgines ens referirem a aquest valuós document, que pot ser íntegrament llegit a l'annex, i que permet un millor coneixement de l'obra. Es conserva una porta en arc de mig punt oberta cap a l'explanada que referíem adés ${ }^{5}$ : aquesta donava accés a una naia, la porxada enlairada en què sol culminar la gran escala que dona accés al pis principal dels palaus. Obrada sobre el pati del castell, la plataforma es cobria amb volta d'aresta ("e lo pas pera entrar en la sala es cuberta de volta de aresta"), protegint l'entrada a la sala, "hun bell portal per on entren a la dita sala obrat de algeps ab sos bells bocells, e basses, e sa bella porta de fusta faxada [amb faixa, una motllura ampla i llisa] e bocellada [amb bocells, motllures convexes de secció semicilíndrica] ab sa tancadura". És a dir, s'havia configurat una portada de guix amb flancs abossellats, amb baquetons adossats que arranquen des de les basses. Respon aquesta sumària descripció al model de portes que trobem en altres construccions de l'època: encara que no s'especifique, suposem que es remataria en forma d'arc de pavelló o cortina, com les mostres que trobem en construccions de l'època com els palaus de Sot de Ferrer o en el dels Pròxita de Llutxent, igualment construïts en guix.

El portal donava pas a una gran estança, la coneguda contemporàniament com Sala Nova, amb seixanta pams de llargària i vint-i-sis d'amplada (uns 13,5 per 5,4 metres), segons les mesures preses d'un informe del 1754 (Sarthou Carreres, 1933-1935, p. 165-166): cal valorar que les bigues emprades en aquests temps solien rondar els cinc metres de llargada, mesures que es corresponen aproximadament a l'ample de la sala. El sòl es trobava pavimentat de rajols de fang cuit, sense cap decoració, simplement "esmolats"; la coberta es configurava com un trespol "de fusta grossa ab copades, parra fulles, enmig listons", a base de jàsseres grosses sobre les que es recolzaven les parafulles o posts, ancorades sobre llistons. Segurament configurava un forjat de cassetons senzill, sense pretensions decoratives, a la manera dels rústics i sòlids trespols que hui encara es poden observar als salons principals de cases com la senyorívola del Sanç, a Vallès. A un dels costats llargs s'obria la porta de la cuina, una menuda estança en què s'obrava una xemeneia, sustentada sobre una barra de ferro de gran pes (ARV, $M R, 9190$, fol. 60v), que assegurava la seua estabilitat. En un dels costats curts s'obria un portal de trets idèntics al de l'accés a la sala, ama-

${ }^{5}$ Si observem la configuració del portal, el seu esplandit es projecta cap al sud, cap a Bixquert, indicant com els batents de la porta es projectaven cap al sud, i no a l'inrevés: és la disposició lògica si teníem en compte que no donava accés a les Sala Vella, suposadament en la plataforma sobre la presó del comte d'Urgell, sinó a la naia. 
gant una escala de caragol que ascendia a la torre de Sant Jordi; al costat, altre caragol davallava a les cavallerisses.

El conjunt, avançàvem inicialment, restava enllestit amb "una bella porxada de fusta grossa, ab tegell, e rajola [ço és, coberta amb un forjat de vareta], e cuberta de teula bastarda, e vers la ciutat fets uns acoberts, e vers Bixquert ses finestres, e damunt la cuyneta una cambra, e fet un caragol pera pugar a la dita porchada", una andana que acollia algunes cambres on s'allotjaven els criats de menor posició del duc, oberta a la manera de porxo vers la ciutat ${ }^{6}$. Si observem una representació contemporània com és la del retaule de Sant Pere, observarem com aquest es manifesta a la manera d'un seguit de vans. En aquests moments les andanes comencen a manifestar-se exteriorment com galeries d'arcades, de traç escarser en els exemples més arcaics ${ }^{7}$, que són citades com porches o porxos': es tracta d'espais plantejats com dipòsits on guardar la collita, on es conserven els productes del camp més imperibles (carabasses, cebes...). Donat que no concebem l'hortet del duc amb un finalitat productora, ens inclinem a pensar que aquest pis alt s'aixecà per ampliar l'espai existent, permetent la construcció d'altres cambres, i especialment per la funció reguladora de la temperatura (el seu sostre actua com a para-sol, donant ombra al forjat de les estances baixes per tractar d'evitar l'excessiu calor estiuenc en elles) que igualment assumeixen aquestes estances.

A grans trets, degué tractar-se d'una estança de bones proporcions, confortable i adaptada per congregar un concurs de visitants important (d'aquestes funcions ens informa la cuina annexa) quan no es practicava el joc de pilota, però sòbria, inclús tosca si es compara amb la refinada arquitectura napolitana de la que el duc pogué gaudir en la seua joventut.

D'aquest gran saló sols es conserva un dels seus costats curts, aquell obrat vers la ciutat, en què perdura una coronella bífora, bastant restaurada (s'ha reposat el mainell): en l'època fou citada com “una bella finestra gran vers la ciutat, ab son bastiment, faxant [...] ab frontises, centerars, e tanques de picaports, e forrellat": Sarthou imaginava, aponat en ella, al duc observant els moviments populars per la Costa del Castell amb motiu de la Germania (Sarthou Carreres, 1926, p. 239). Resulta destacable l'atenció parada a aquest element

${ }^{6}$ Els peus dels arcs sobre els que es sustentava encara s'aprecien en algunes imatges d'inicis del segle XX: Sarthou Carreres, 1922, p. 57.

7 Podem assenyalar, a la mateixa Xàtiva, les andanes de l'Hospital de l'Assumpció o les de les cases $n^{\circ} 13,15$ i 17 del carrer Botigues, originalment un sòl edifici, de cronologia aproximadament contemporània.

8 Així trobem citada l'andana en l'inventari potmortem dels bens de Guerau de Castellvert, senyor del Genovès (1500): “Ítem, en lo porche, dalt la casa...". Soler, 2007, p. 339. 
en concret, no sols en el temps invertit en la seua construcció (dilatada, especialment pel que fa als seus elements de fusteria, entre juliol i octubre del 1516) sinó en la individualització que es fa patent en referir-la: apareix citada com la "finestra maior" o com la "finestra gran" de la Sala Nova, mentre la resta de vans sols es fan explícits, i de forma no excessivament clara, en la visura final. Inclús es protegeix per una porxada o voladís (ARV, $M R, 9190$, fol. 48v), tot i no resultar excessivament necessària, tractant-se d'un element més adequat a les finestres obertes al sud, vers la solana de Bixquert. La voluntat d'obrar aquesta finestra vers la ciutat amb distinció i bellesa són evidents, i presenten una sèrie d'implicacions: cal plantejar com es tracta d'un element que assumeix uns trets, i especialment una significació, més enllà de les seues funcions purament utilitàries. És un va que permet il-luminar i ventilar l'interior, però per les seues dimensions, la seua monumentalitat (es segueix el prototipus de la finestra de corbes o coronella, sempre en relació amb els espais de poder i amb el caràcter parell dels seus habitants) i l'afegit de festejadors sense dubte poden identificar-se les funcions amb les que es construïa: per a procurar "el solaz ante el paisaje y el trasiego humano, y para participar de las fiestas y actos de representatividad", però sempre des d'una posició enlairada, marcant un control, si de cas visual, sobre les activitats desenvolupades més enllà dels murs (Arciniega García, 2015, p. 243). En el darrer apartat tractarem d'argumentar com es configura, per contra, la mirada des de la ciutat vers les estances del duc i el paper obrat en aquesta per la finestra.

Vers la vall de Bixquert s'obrien altres tres finestres, segurament de proporcions quadrades, que es citen com "de bona grandaria". Com la gran coronella del flanc nord, es tancaven " $a b$ sos bastimets de fusta de enterars, faxats e bocellats ab ses frontes, picaports e forrellats" (ARV, MR, fols. 63v-64r), que permetien gaudir de llum natural a l'hora que s'assegurava cap mena de fugida de la pilota cap a l'exterior.

Si tenim en compte la distribució dels casals nobiliaris valencians del segle XV, advertirem que les estances del pis noble s'ordenaven atenent les seues funcions: les habitacions de caire més públic, el menjador i la gran sala principal (ací amb funcions de trinquet) es situaven més prop de l'accés, de l'escala i naia. Tot seguit es trobaven les cuines i rebost. Finalment, i en l'espai més recòndit, d'accés més restringit, es trobaven els retrets o recambres i les alcoves o habitacions. En la casa del senyor duc dites alcoves devien obrir-se cap a Bixquert, ço és, el costat diametralment oposat a l'accés del pis, i inclö̈en les dites Sales Velles o Morisques. Devia contar-se amb diverses alcoves, les necessàries per allotjar dignament l'egregi presoner, com es cita al duc en l'època, i al seus acompanyants. Recapitulant allò exposat, observarem com els trets assenyalats no sols per a la Sala Nova, sinó en general per a la configuració 
dels edificis bastits com a residència de Ferran d'Aragó es corresponen als models perceptibles en l'arquitectura residencial de l'època.

\section{ELS ARTÍFEXS}

En l'obra, com ja avançàvem, hi participa un destacat nombre d'artífexs. Cal citar, en primer lloc, a Jerònim Monyos, mestre obrer de vil·la, que sembla fou el principal contractant de l'obra de la cisterna i la sala: és fins a cert punt probable que es trobés vinculat amb algun gènere de parentesc amb l'homònima família de fusters, especialitzats en la talla i l'obra en guix, que treballen contemporàniament a Xàtiva, i més endavant a València (Bérchez, Gómez-Ferrer, 2007, pp. 352-353; Pascual Montell, 2020, pp. 81-82, nota 20), però les referències documentals són massa escasses com per assegurar cap possibilitat. El treball de Monyos degué resultar satisfactori, ja que passà a encarregar-se de les obres empreses al castell almenys en 1519 i 1520, sempre dirigint un destacable grup de mestres i obrers, encarregant-se de tasques diverses. En la comentada visura és l'únic mestre citat com a constructor de l'obra, si bé hi participaren altres: sobre el mestre Miquel Fuster va recaure la direcció de l'obra de l'aljub, ja que s'explicita la seua participació com a únic mestre present durant la majoria de dies que es treballa en aquesta construcció (ARV, $M R$, fols. 1r-20r), i reapareixerà amb freqüència en l'obra de la sala. És possible que actués com a subrogat del principal contractant, Monyos, encarregant-se d'una obra de menor lluïment, reservant-se aquest la direcció de la principal part de la fàbrica.

En els inicis de la construcció de la sala (ARV, $M R$, fol. 21r, 27 de març), en la que tornem a parar la nostra atenció, apareixen els avantdits obrers de vil·la i, per primera vegada, Domingo Lopiz o López, mestre fuster: en diverses ocasions durant els mesos següents, mentre els obrers treballen amb una destacada quadrilla, es reincorporarà puntualment i, en totes aquestes ocasions, sols per un dia: plantejant el ritme de l'obra, que es trobaria als seus inicis, és ben possible que la seua tasca fos la d'elevar bastiments i andamis. La mateixa tasca realitzarien, possiblement, els fusters Joan Sans i Pere Blasco, que s'uneixen a l'obra el 21 i 22 d'abril (ARV, $M R$, fols. 29r-29v), documentant-se en altres ocasions, junta o separadament: per exemple, Monyos i Blasco s'encarregaven del bastiment per a la gran finestra de la sala el 26 de juny, incorporant-se a l'endemà Sans, i tots tres en conjunt treballen en les portes de l'estança, des del 30 de juny (ARV, MR, fols. 40r i 40v). Darrerament participa Joan Pérez, també mestre fuster (ARV, $M R$, fol. 47v, 8 d'agost), quan l'obra es trobava molt avançada. 
Juntament amb aquests treballarà una partida d'homes, variable pel que fa als seus efectius, que en ocasions es composa d'un parell de manobres sota les ordres d'un mestre però que, en els moments de màxima feina, arriba als deu obrers, comptant manobres i arriers. Trobarem treballant, amb obrers procedents de la ciutat -que constitueixen una part majoritària de l'equip-, altres que es citen com "manobres del castell": segurament es tractava de guardes i empleats en la fortalesa que, en èpoques d'escassa activitat militar, com la present, podien veure augmentats els seus beneficis amb la feina extra d'ajudar en les obres. Podem plantejar el seu limitat paper com a mà d'obra especialitzada: sols els manobres de la ciutat apareixen en feines de compromís com la preparació del morter o l'esmolat de les rajoles per al sòl.

En la mateixa categoria cal que incloguem els manobres que, per comptar en el seu poder amb una bèstia -cavall, matxo, ase- s'encarreguen de la feina com arriers, transportant aigua, argamassa i altres materials a l'obra. Les diferències entre ells es fan evidents, fonamentalment, en els salaris que perceben 9 : el dels mestres ascendeix als cinc sous diaris, mentre el dels manobres de la ciutat es limita als dos sous i set diners, sobrepassant el dels castellans, de sols dos sous. Segurament l'afegit dels set diners responia al desplaçament que els primers devien realitzar cada matí fins al castell. Igualment, els arriers cobren tres sous i set diners, car no sols es desplaçaven des de la ciutat sinó que, a més, aportaven l'animal.

És destacada igualment la participació d'artífexs musulmans. Primerament documentem a Çaat Porhella, manobre, que entre el 26 i 30 de maig realitza els enfilats de les finestres (ARV, $M R$, fols. 35r-35v): quasi enllestida l'obra s'incorpora Azmet Paxey, que treballa entre el 9 i 12 de juliol, i més endavant Alí Catala, el 30 d'eixe mes (ARV, MR, fols. 43v i 47r). Més destacada sembla la incorporació, en qualitat de mestre d'obra, d'Ubaydal Fandaqui. La participació de tots quatre, procedents del raval de Xàtiva, és força suggestiva: a Porhella sols se'l documenta realitzant els filats, però els dos manobres i Fandaqui apareixen en igualtat de condicions respecte els mestres i manobres cristians, cobrant idèntics salaris, però sols quan les obres es troben gairebé enllestides, $i$ durant un lapsus de temps força breu. Resulta aventurat atribuir-los cap gènere específic de feina, però pels trets comentats respecte la seua incorporació pen-

${ }^{9}$ Respecte els modes de contractació i pagament de salaris, s'observa una continuïtat respecte el segle XV: els mestres i manobres eren contractats diàriament, assegurant un major control sobre l'obra i els pressupostos. També s'adverteixen similituds pel que fa a la configuració de les quadrilles. Vid. García Marsilla, 1997, pp. 480-483; García Marsilla, 2003, p. 9, pp. 10-11 respectivament. Sobre el paper que pogueren assumir els obrers del castell i els arriers, sempre per al segle XV, García Marsilla, 1997, pp. 483-485. 
sem plausible que restaren sota la seua responsabilitat la realització de tasques d'ornamentació de l'espai ${ }^{10}$ : d'altra banda, valorem com Ubaydal participa, amb els manobres Alí Català, Axer Addet i Ader Botella en els murs de l'hort del duc per reparar els mals ocasionats "per les grans aygues de les pluges" d'inicis de novembre (ARV, $M R$, fol. 56v), és a dir, en unes feines allunyades de les curoses tasques decoratives que poguérem plantejar sota la seua responsabilitat en la Sala Nova.

Una sèrie de dades destacades que aporten els comptes es dirigeixen al coneixement d'aquells que proporcionen material a l'obra: ferrers, mercaders, rajolers, fusters, algepsers i calciners, de la ciutat o dels pobles propers (Manuel, Sallent), moros o cristians ${ }^{11} \ldots$ els mestres encarreguen des de peces ceràmiques, com cànters, a aplics de forja, com l'aixeta de l'aljub, des d'almodins de calç i barcelles d'algeps a pegunta, frontisses, vernissos o oli per lacar encadufades. A més d'obrir-nos altra via a partir de la qual acostar-nos a la construcció de les parts del castell que ens ocupen, aquestes anotacions amplien les informacions que disposem sobre la distribució del treball artesanal en certs sectors relacionats amb la construcció, a nivell social però també geogràfic, en Xàtiva i la seua àrea més propera.

\section{LA DESTRUCCIÓ COM EPÍLEG}

Retornat el presoner a la llibertat per reial disposició, desapareix la raó de ser per les que es construïren les sales noves. En diverses ocasions trobem ressenyades les despeses ocasionades amb les reparacions fetes en elles, i sabem que es seguiren emprant amb diferents finalitats: per exemple, vers la meitat del segle XVI servien per emmagatzemar les armes confiscades als cristians nous (Ventura Conejero, 1998, p. 268). Hem de pensar que les construccions

${ }^{10}$ Es tracta solament d'una hipòtesis de partida plantejada en base a la cronologia de l'actuació dels obrers i la imprecisió dels comptes quant a la feina desenvolupada per cadascun d'ells. D'igual forma, no podem perdre de vista que la tasca de treball del guix podria estar directament vinculada amb els esmentats fusters Monyos, que podrien vincular-se en algun grau de parentesc, com dèiem de moment desconegut, amb el principal contractant de l'obra. De totes formes, els comptes són molt detallats respecte els artífexs participants i en cap moment esmenten la intervenció del fuster més destacat de la nissaga en aquest moment, Lluis Monyos, o altre dels integrants de la mateixa, en el procés constructiu.

${ }^{11}$ En general, per a l'aprovisionament dels materials bàsics de construcció, el panorama no sembla presentar massa canvis respecte l'exposat per García Marsilla, 1997, pp. 485489, si bé en el cas que ens ocupa cal que afegim una sèrie de peces de caire sumptuari que no tenien lloc en obres com les empreses al castell en el segle XV. 
llanguiren progressivament, però encara es mantenien dempeus a mitjans del segle XVIII: el seu estat de degradació devia agreujar-se a mesura que avançava el temps, accentuat a més per l'alarmant descens de fons destinats des de la Monarquia al sosteniment del castell. El devastador terratrèmol del 1748, conegut com de Montesa, va suposar un colp fatal per a la conservació del conjunt fortificat: més que cap guerra o setge, fou aquest el succés que més palpablement va afectar les seues construccions. La matinada del 23 de març els sotracs tombaven "la mas elevada, fuerte y eminente torre del Castillo, llamada communmente del Duque de Calabria, a pesar de su fortaleza y su resistencia, le quitó la techumbre, dejandola quebrada por varias partes", segons la crònica contemporània del capítol de la col-legiata de Xàtiva (Arxiu de la Col·legiata de Xàtiva, Actes Capitulars, 1745-1748, 2.1.2-09, fol. 174r i v) i ensorraven altres estructures del complex, però sembla que les estances del duc resistiren malmeses, i l'any següent encara es conservaven mitjanament senceres: Sarthou publicà extractes d'un informe (Sarthou Carreres, 1933-1935, pp. 165-166) redactat el 30 d'agost del 1749 pels mestres Soler i Blasco, obrer i fuster respectivament, amb motiu de la seua utilització per empresonar en elles a " $m u$ chas gitanas y sus hijos", i en què analitzaven l'estat del castell després del terratrèmol. Ressenya dit escrit l'existència encara de la dita sala del duque de Calabria (devia tractar-se de la Sala Nova), a la que s'annexaven una sèrie de sales i habitacions, que devien correspondre's amb les Sales Velles. A sobre es trobava un altre saló amb les mateixes mesures, l'andana. A més, es citen junt aquestes estances dos calabossos "debajo la [torre de la] campana de 30 palmos en cuadro, recayentes sobre una profunda cisterna", ço és, les cel·les del comte d'Urgell.

Però a finals de segle l'edifici del cinc-cents devia trobar-se en un avançat estat de destrucció. Una bona mostra són les impressions d'Antonio Ponz: «dá lastima ver que una magnífica habitacion, en donde estuvo preso el Duque de Calabria, se está acabando de destruir: escaleras, patios, cisternas, y lo demas caerá todo brevemente. Aún vivia el Gobernador allí, no hace muchos años, hasta que se dió el fallo de abandonarlo» (Ponz, 1779, tom IV, p. 267-269). No dubta l'abate entorn la causa de la ruïna del complex: la descura, ocasionada en gran mesura per la pèrdua de les funcions del recinte. El procés, que es prolongava sense solució de continuïtat des de més d'un segle enrere, arribava ara a extrems d'assolament molt accentuats.

En 1800 es va procedir al desmantellament de les sales: restant quasi enderrocades les estances del duc, el corregidor Gaspar Pascual de Bonanza formava expedient per a efectuar el desmuntatge de les peces de fusta existents entre les seues ruïnes, ja que es trobava el castell perdent-se i el fustam exposat als visitants que pujaven d'excursió i guisaven allí el seu menjar. S'encarrega la tasca 
als mestres José Lacosta i Antonio Jover, fuster i obrer respectivament, i a l'arquitecte Francisco Cuenca. Varen emetre una relació de les peces aprofitables que paga la pena citar: vint files (o bigues) de 24 pams de llarg (uns 5,4 m, corresponent-se a l'amplada de la sala), quatre revoltons i tres cornises de les mateixes dimensions (segurament parts del mateix sostre), a més d'altres peces de les que no es ressenya la tipologia. S'encarregà a l'arquitecte Cuenca que, ajudat de bracers, baixés totes aquestes restes a poblat, on es subhastaren el 30 de juliol d'aquest any. Els epígons de l'esplendor conferit a les sales es remataren per 207 lliures l'obrer xativí Miguel Martínez, i amb allò cobrat es va acabar l'obra del passeig de l'Albereda (Sarthou Carreres, 1933-1935, pp. 164-165).

De la presó del duc poc quedà més enllà de la seua memòria. En la tria d'imatges que reflecteixen l'aspecte exterior del castell observarem com es para una especial cura des del segle XVI al XVIII a la captació detallada d'aquestes estances, quelcom que ens ha permès aproximar-nos, almenys, al seu aspecte exterior. Enderrocat l'edifici, sortosament es conservà el mur on s'obrava la finestra de la sala oberta a la ciutat. El recull d'autors que durant el segle XVIII parlen del castell (Espinalt, Ponz) mostra com restà memòria de la presó del duc a la ciutat, com aquest esdeveniment es mantenia en la memòria no sols dels ciutadans, sinó també dels visitants, que paraven esment de la curiositat. Si comparem les referències de dos casos paral·lels, com són els empresonaments del duc d'Urgell i del de Calàbria, observarem com les referències a aquest darrer són -fins a cert punt- abundants al XVIII: La rememoració dels tràgics anys finals de Jaume d'Urgell cobrarà força, especialment, al XIX, de la mà de la Renaixença i per raons diferents a les que apuntàvem per al cas de Ferran d'Aragó: la seua evocació ja no caurà en l'oblit, presentant-se conjuntament com els habitants més importants del castell. Resulta temptador tractar de relacionar la remembrança del duc de Calàbria amb la possibilitat d'establir relacions visuals des de la ciutat envers les estances, manifestades exteriorment per la particular finestra, i després de l'enderroc amb l'escarit puntal que restà, albergant encara la coronella. Resultaria, a la fi, una mena de correlat del paper visual que plantejàvem per a la finestra des de la posició del duc: en aquests anys la finestra ja no era el seu mirador privilegiat des del que s'ensenyoria de Xàtiva, tampoc el punt a través del qual "el interior queda al descubierto" i és aparador dels luxes de l'estança (Arciniega García, 2015, p. 246), més bé esdevé un punt fonamental en què es concentra el relat bastit entorn la figura del duc, unes funcions que assumeix satisfactòriament per la seua posició privilegiada i característiques particulars.

La imatge del fosc parament contra el clar del cel, emmarcant el perfil mixtilini de la coronella resultà temptador per a la majoria de visitants al castell als segle XIX i XX: és aquesta una de les estampes triades pel viatger romàntic 


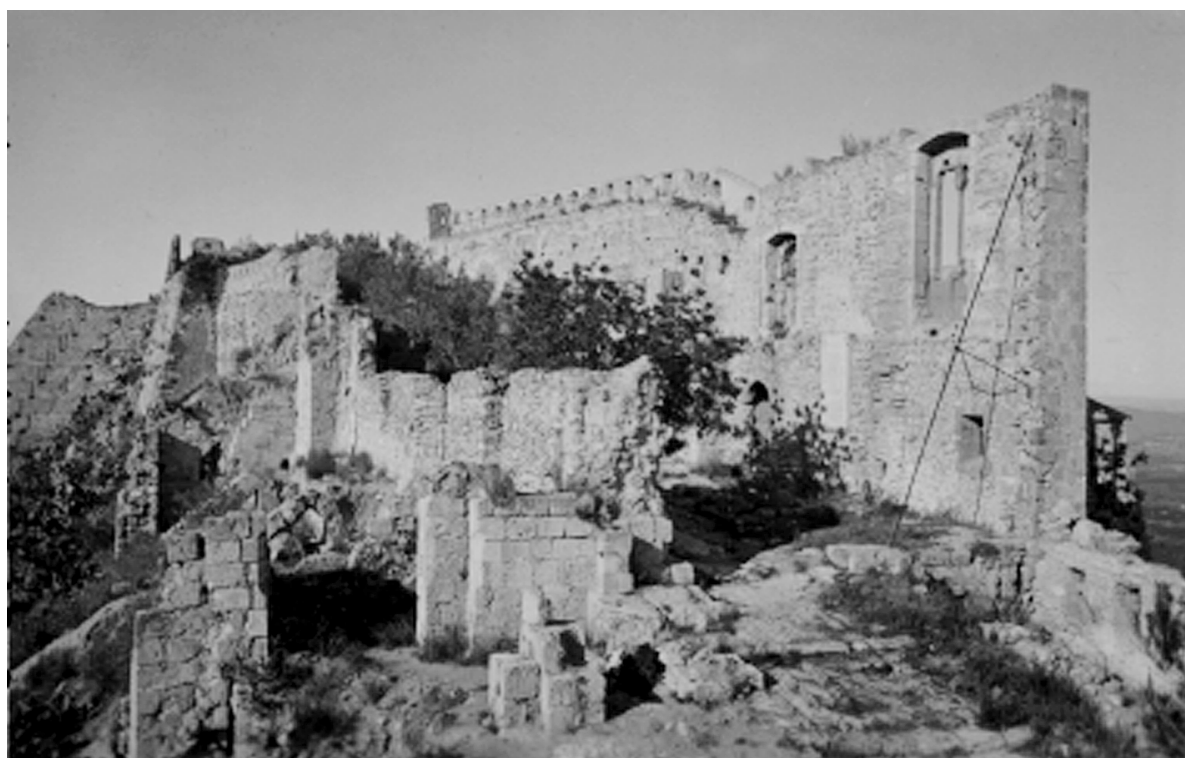

Figura 6. Exterior i accés a les estances del Duc de Calàbria. AHMX, Fons Loty, vers 1920.

Richard Ford en 1831 per captar-la a l'aquarel-la, durant la seua visita a la ciutat, amb acusats tints romàntics, o pel fotògraf Antonio Passaporte, enviat per la casa Loty a la ciutat a inicis dels anys 1920 (Figura 6). Més abundants són les fotografies de Sarthou que paren atenció a aquesta estructura, esmentada en clau elegíaca en distintes publicacions al llarg dels anys (Sarthou Carreres, 1926, p. 239): important resulta, igualment, la tasca de difusió de les imatges, realitzada, especialment, a partir de la publicació d'articles en revistes de tirada nacional i dels seus populars llibres (Sarthou Carreres, 1922, pp. 48, 57, 64, 75, $76,80-81$ ), il·lustrats amb elles. La finestra pren, inclús, cert paper en les recreacions literàries empreses entorn la figura del duc: "En la gran sala hallábase el Duque indolentemente reclinado en un poyete que, revestido de mullida alfombra, no lejos de la ventana se aparecía" (Reig, 1914, s/p) i en les recensions històrico-descriptives entorn el castell: "si ese ventanal, esos mudos sillares que desafían al tiempo y a los hombres pudiesen hablar iqué cosas tan interesantes, tan tristes y tan graves nos contarían!" (Sarthou Carreres, 1922, p. 75). D'ençà el segle XIX i XX es crea una imatge concreta entorn la finestra, que des del seu aparent equilibri perenne segueix presentant-se al visitant actual com una destilllada romanència de la infortunada i tràgica història de Ferran 
d'Aragó, percepció acendrada per la placa laudatòria que presideix les seues restes, rebent al visitant: "Este ventanal es lo que queda de la Sala del Duque. Aquí gimieron egregios prisioneros... y en esta sala consumió los diez mejores años de su juventud el duque de Calabria".

\section{CONCLUSIONS}

Passats més de tres-cents anys dels inicis de la decadència del mateix, l'estat de desfeta del castell actualment és total: s'han conservat algunes petites joies, com la capella de Santa Maria, mesclades amb recreacions goticistes i vestigis arqueològics, en molts cassos mancats d'una anàlisi en profunditat. Pensem que, amb aquest estudi, hem esbossat un primer acostament a un d'aquests espais arqueològics, les estances del duc, tot analitzant la composició arquitectònica que les ruïnes ens proporcionen, contrastant-les amb els documents (també amb les suposades fonts gràfiques) existents.

Revisades aquestes estructures concloem que, als nostres ulls, l'habitatge adaptat per a Ferran d'Aragó pot constituir un exemple representatiu de l'arquitectura residencial en el trànsit dels segles XV al XVI en el País Valencià, una mostra més de la cultura arquitectònica civil de l'època. Plantegem aquesta afirmació tot basant-nos en l'existència d'una disposició (per exemple, en la diferenciació entre espais públics i privats), tècniques (tals com l'ús destacat de l'algeps, especialment en elements de caire ornamental) i elements arquitectònics (des de la porta motllurada a les escales de caragol o els forjats) que és possible observar i documentar en obres coetànies, com s'ha comentat al llarg del text.

Un dels punts en què pot raure l'interès de dites estructures és l'important volum documental que s'hi generà contemporàniament a la seua construcció i que, cas estrany per a un edifici civil en Xàtiva, s'ha conservat, precisament per derivar-se dits documents cap a la capital, en tractar-se d'una obra promoguda des d'instàncies superiors. Són abundants les residències urbanes locals bastides per aquests mateixos anys, però en la majoria de cassos han arribat a l'actualitat en diversos graus de transformació i, especialment, mancant d'un suport documental que possibilite aprofundir en el seu estudi en termes com la configuració de l'estructura original, les funcions de les estances, l'autoria, l'organització de la construcció a nivell social... fent necessari de recórrer, en molts cassos, a l'anàlisi de fonts secundàries per aprofundir en cadascun d'aquests camps. Analitzar el cas de les estances de Ferran d'Aragó pot resultar interessant, en tant que enriquidor, per a l'estudi d'aquests ítems en el camp de l'arquitectura del segle XVI no sols en el context local, sinó que es pot fer extensible a tot l'àmbit valencià. 


\section{ANNEX}

ARV, Mestre Racional, 9190, Conters de les obres del Castell de Xativa del any MCDXVI, fols. 63v-64r.

El 23 de gener del 1517, acabades les obres efectuades per Jerònim Monyos en la Sala Nova i l'aljub de l'hort del duc de Calàbria, el notari Jerònim Monfort, per ordre del batlle, realitza una visura amb assistència dels mestres d'obra Bernat Sans i Jerònim Martorell. Es valoren les obres 10.467 sous i 7 diners.

"[63v] En lo dit e mateix dia, comptats vint [i] tres de giner del dit any Mil Cinchcents desset, de provisió [i] manament del dit magnifich lochtinent de batlle, yo, en G[uillem] Monfort, notari, [...]irra dessús de en temps ab lo dit [mestre Jerònim] Monyos, obrer de vila, e de les dites obres, muntí al [ca]stell per [...] les o[br] es que en lo any passat Mil Cinch[cen] ts setze, eo per tot lo dit any, foren stades atrobades. E així viu com la dita sala nova que en lo dit castell era stada obrada de manament de la Reyal Magestat per a jugar a pilota, e deport del Illustre Senyor Duch, don Ferrando, la qual és stada feta e obrada junta ab la torre de Sent Jordi del dit Castell, era atrobada a obrar molt bé ab tot compliment, pa[vi]mentada de ragola comuna de ayment, e reparada, ab sa bella cuberta de fusta grossa, ab copades, parra fulles, enmig listons e feta una bella finestra gran vers la ciutat ab son bastiment, faxant [...] ab frontises, centerars, e tanques de picaports, e forrellat. E per semblant hi havia fetes tres finestres vers Bixquert de bona grandària, ab sos bastimets de fusta, de

[64r] encerats, faxats e bocellats, ab ses frontes, picaports e forrellats, \& encara fets [...] filats de corda de cànem de fora les dites finestres, ab sos bastiments de fusta, e baldes de ferro, perquè no caygua la pilota. \& així mateix hi havia hun bell portal per on entren a la dita sala, obrat de algeps, ab sos bells bocells, e basses, e sa bella porta de fusta faxada e bocellada, ab sa tanquadura. \&, per semblant, hi havia [...] altre portal al cap de la dita sala, e feta una scala pera pugar a la torre de Sent Jordi, ab sa bella porta faxada e bocellada, e tancadures de ferro, e anelles en les dites portes de la sala. E així mateix encara feta prop e junt ab dita sala una cuyna, encara ab sa ximenea e porta de fusta ab bastiment, frontises, e tanca. E altra porta al costat de aquella, de la mateixa maña, ab hun caragol que davallen davall la sala a una cavalleriza. E damunt la sala he havia obrada una bella porxada de fusta grossa ab tegell, e rajola, e cuberta de teula bastarda, e vers la ciutat fets uns acoberts, e vers Bixquert ses finestres, e damunt la cuyneta una cambra, e fet un caragol per a pugar a la dita porchada. \& la cuyna, e lo pas pera entrar en la sala és cuberta de volta de aresta; veritat es que lo enfront de la dita sala de fora vers la Ciutat resta que fa tot a reboçar de argamassa prima, e après reparar, eo de la mateixa argamassa per que·n ey bat molt fort la prohença, e no ses pogut fer en lo dit any per e averhi altres necessitats de obres. E així mateix fonc [visurat] lo dit Aljub del portal de Santa Maria com era atrobat de obrar, e fer sols sols [sic], entresols en lo dit aljub ab argamassa prima, molt 
ben pi[cada], e les parets de dintre reparades. \& feta una paret de argamassa ab ses pedres vers lo molí, grossa, de amplaria de huyt o nou palms per respatle del dit Aljub, e arrassar, e acabar de la part de dalt, o damunt, e adobar sos scorredores perquè les aygues entren en lo dit Aljub, e reparar de part de damunt, e feta una scala, e una porta ab son portal perque stiga tancat, e guardat. \& més hi ha una trompa de plom ab hun grifo de coure per hon va laygua [...] dona en hun caffareng per a regar l'ort del Don Illustre Duchc \& en lo dit ort a les spatles del moli es stada feta una longeta, reparada e paymentada per a deport del Don Señor Duch, \& de les parets del dit ort que eren caygudes, a causa de les gran aygues, tornades a fer de argila [...], e pedres, totes les $q[\mathrm{uals}]$ obres fetes així les atrobades com algunes no atrobades foren Scrist [...] molt ben[...] cobrades ab tot compliment a servey de la Reyal Maiestat conserm[...], e de mano del Don castellà. \& així resten algunes altres obres concitades per acabar de obrar en lo present any. De totes les qua[1s] dites coses yo dit notari, e scrivà rebí acte públic, a instancia del Don [H]onor[able] Ffrancesch Abril, notari loctinent de receptor reyal de [la ciutat].

Presents, testimonis [de] les dites coses, en Bernat Sans e en Gerònim Martorell, [...] obrers de vila, de la ciutat de Xàtiva."

\section{BIBLIOGRAFIA}

ARCINIEGA GARCÍA, L. (2015): "Los ojos de la arquitectura. Espacios para ver y ser visto". Brouquet, S., García Marsilla, J. L. (ed. lit.). Mercados del Lujo, Mercados del Arte. El gusto de las elites mediterráneas en los siglos XIV y XV. Valencia: Universitat de València, pp. 241-270.

BALLESTER JULBE, C. (1909): La Germania en Játiva. Murcia, Tipografia de Alejandro Saenz Huertas, 109 p.

BÉRCHEZ, J.; GÓMEZ-FERRER, M. (2007): “Arquitectura de la época moderna en Xàtiva”. Company, X., Pons, V., Aliaga, J. (coms.). La Llum de les Imatges. Lux Mundi. Xàtiva 2007. Llibre d'estudis. València, Generalitat Valenciana, pp. 351-373.

BOIX RICARTE, Vicente (1857): Xàtiva: memorias, recuerdos y tradiciones de esta antigua ciudad. Xàtiva, Imprenta de Blai Bellver, 439 p.

CASTEÑEDA ALCOVER, V. (1911): “Don Fernando de Aragón, duque de Calabria. Apuntes biográficos", Revista de Archivos, Bibliotecas y Museos, 25, II, pp. 268-286.

CABEZA SÁNCHEZ-ALBORNOZ, M. C.; TOSCANO, G. (1999): La Biblioteca Reial de Nàpols: d'Alfons el Magnànim al duc de Calabria, 1442-1550. València, Generalitat Valenciana, 149 p.

ESPINALT GARCÍA, B. (1786): Atlante Español ó Descripcion general geográfica, cronológica, è histórica de España, por reynos y provincias, Madrid, Imprenta de Hilario Santos Alonso, vol. IX, 279 p.

FALOMIR FAUS, M. (1994): "El duque de Calabria, Mencia de Mendoza y los inicios del coleccionismo pictórico en la Valencia del Renacimiento", Ars Longa, 5, pp. 121124. 
FERRER DEL RIO, E. (2016): “El duc de Calábria, un presoner reial a Xàtiva”, Pintura i patrimoni històric a Xàtiva. Actes de les VII Jornades d'Art i Història, Xàtiva, Ulleye, pp. 65-119.

GARCÍA CARCEL, R. (1981), Las germanías de Valencia, Barcelona, Península, 318 p. GÓMEZ-FERRER LOZANO, M (2002): Vocabulario de arquitectura valenciana. Siglos XV al XVII, València, Ajuntament de València, 2002, 289 p.

GARCÍA MARSILLA, J. V. (1997): "El mantenimiento de los recintos fortificados en la Valencia bajomedieval. Las reparaciones en el castillo de Xàtiva (1410-1412)", Acta historica et archeologica mediaevalia, 18, pp. 475-493.

GARCÍA MARSILLA, J. V. (2003): "Las obras que nunca se acaban. El mantenimiento de los castillos en la Valencia medieval: sus protagonistas y sus materiales". Ars Longa, 12, pp. 7-15.

IÑÚRRIA MONTERO, V. (2013): "Estudi històrico-evolutiu del joc de pilota concretat en la pilota valenciana", Faixa Roja, faixa blava. La pilota valenciana. València, Museu Valencià d'Etnologia-Museu de la Pilota del Genovés, pp. 38-47.

MARTÍ FERRANDO, J. (1993): Poder y sociedad durante el virreinato del duque de Calabria: (1536-1550), València, Universitat de València-Departament d'Història Moderna. Vols. I-IV.

PEREA RODRÍGUEZ, O. (2006): "La noblesa valenciana en el Cancionero General: l'exemple de Francesc Gilabert de Fenollet (ca. 1480-1548), batlle de Xàtiva”, Primer Congrés d'Història de la Costera. València, Alfons el Magnànim, pp. 365-382.

PASCUAL MONTELL, V. G. (2020): “Arquitectura conventual a Xàtiva entorn les Germanies”. La Germania a Xàtiva. Actes de les XI Jornades d'Art i Històra, Xàtiva, Ulleye, pp. 72-117.

PONS ALÓS, V., CRUSELLES, J. M. (coord.). (2006) “Xàtiva en la Edad Media”, en Hermosilla Pla, J. (dir.), Historia de Xàtiva, València, PUV, 525 p.

PONZ, A. (1779): Viage de España: en que se da noticia de las cosas mas apreciables y dignas de saberse, que hay en ella. Madrid, Imprenta de D. Joachin Ibarra. Tom IV, $262 \mathrm{p}$.

REIG, G. (1914): "En el castillo de Játiva", La Esfera, 198, s/p.

SARTHOU CARRERES, C. (1914): "Los famosos códices miniados del duque de Calabria”, La Esfera, 736, pp. 26-27.

SARTHOU CARRERES, C. (1922): El Alcázar setabense. Valencia, Tipografía Moderna, $90 \mathrm{p}$.

SARTHOU CARRERES, C. (1926): "Los egregios prisioneros del castillo de Játiva", Boletín de la Real Academia de Historia, 18, pp. 216-240.

SARTHOU CARRERES, C. (1933-1935): Datos para la historia de Játiva, v. III. Xàtiva, Imprenta Sucesora de Bellver, $415 \mathrm{p}$.

SARTHOU CARRERES, C. (1979): Castillos de España. Madrid, Espasa-Calpe, 501 p. SILVA SANTA-CRUZ, N. (2005): "La Corte de los Reyes Católicos y el reino nazarí. Permeabilidad cultural e intercambios artísticos", en Checa, F., García García, B. J. (ed.), El arte en la Corte de los Reyes Católicos. Rutas artísticas a principios de la Edad Moderna. Madrid, Fundación Carlos de Amberes, pp. 267-286. 
SOLER, A. (2007): Genovés. Geografia, història, patrimoni. Genovès, Ajuntament del Genovès, $379 \mathrm{p}$.

VALLÉS BORRÁS, V. J. (2000): La Germanía. València, Alfons el Magnànim, 462 p. VALLÉS BORRÀS, V. J. (2007): “L'enfrontament del Marqués del Zenete i Vicent Peris", Papers de la Costera, 2007, pp. 13-28.

VENTURA CONEJERO, A. (1998): El castell de Xàtiva, Xàtiva, Mateu Editors, 289 p.

VICIANA, M. de. (1564) Libro tercero de la Chronica de la inclita y coronada ciudad de Valencia y de su reyno. València, Juan Navarro, 178 fol. 